\title{
Minireview
}

\section{Recent Advances in the Study of the Genotypic Diversity and Ecology of Listeria monocytogenes}

\author{
BON KIMURA ${ }^{1 *}$ \\ ${ }^{1}$ Department of Food Science and Technology, Faculty of Marine Science, Tokyo University of Marine Science \\ and Technology, 4-5-7 Konan, Minato-ku, Tokyo 108-8477, Japan
}

(Received February 27, 2006-Accepted April 18, 2006)

Listeria monocytogenes, an intracellular pathogen, is the causative agent of listeriosis, a serious epidemic and sporadic food-borne disease. The clinical manifestations of listeriosis include meningitis, meningoencephalitis, septicemia, spontaneous abortion, perinatal infections, and gastroenteritis. Although rare in comparison to other food-borne diseases, listeriosis has a high rate of lethality (about 30\%), making L. monocytogenes an important pathogen. L. monocytogenes can survive in a broad range of ecological niches, including farm environments and food-processing plants and in a wide range of hosts, including humans and many species of mammals. Furthermore, the capacity to adapt and survive under extreme conditions allows this bacterium to exist ubiquitously in the environment and to survive and proliferate under conditions within the food supply. Although the study of $L$. monocytogenes has already been extensively reviewed, knowledge about this pathogen has been expanding rapidly. Against the background of the growing body of information on this bacterium, the present review mostly discusses advances made in the study of this pathogen over the last 5 years.

Key words: Listeria monocytogenes, food pathogens

\section{Introduction}

Listeria monocytogenes, a Gram-positive foodborne pathogen, is responsible for listeriosis, which has an overall mortality rate in humans of $30 \%$, manifesting as clinically asymptomatic fecal carriage, febrile gastroenteritis, severe mother-to-child infections, and central nervous system infections ${ }^{59)}$. Although the incidence of listeriosis is low ${ }^{13)}$, Listeria monocytogenes is second only to Salmonella spp. in the estimated number of food-related deaths it causes in the United States ${ }^{38)}$, and food-borne transmission is the main route of listeriosis infection ${ }^{13)}$.

Six species of the genus Listeria are currently recognized: Listeria monocytogenes, Listeria innocua, Listeria

\footnotetext{
* Corresponding author; E-mail: kimubo@s.kaiyodai.ac.jp, Tel: +81-3-5463-0603, FAX: +81-3-5463-0603
}

ivanovii, Listeria seeligeri, Listeria welshimeri and Listeria grayi. Of these, only two species are considered to be pathogenic, L. monocytogenes in humans and L. ivanovii in other mammals. Most human infections by L. monocytogenes are attributed to the consumption of contaminated food. This pathogen usually affects susceptible individuals such as the elderly, pregnant women, newborn babies or fetuses. Symptoms are flu-like for healthy persons, but severe complications, such as meningitis, septicaemia, spontaneous abortion or listeriosis of the newborn ${ }^{64)}$, may occur. Pregnant women are most susceptible to this pathogen, accounting for approximately $35 \%$ of all cases worldwide ${ }^{56)}$. Active surveillance in the United States showed that L. monocytogenes is the second leading cause of bacterial meningitis in patients younger than 1 month or older than 60 years ${ }^{55)}$. The number of cases of listeriosis averaged 100 per year from 1993 to 1997 in the $\mathrm{USA}^{4}$ ). A recent study in Japan ${ }^{26,45)}$ 
estimated that the number of listeriosis cases has averaged 83 per year since 1996.

\section{Genetic Properties of L. monocytogenes}

While many different strains of L. monocytogenes have been isolated from food and food processing plant environments, only a few virulent strains are known to cause listeriosis ${ }^{58)}$. Therefore, accurate tracing of L. monocyotoges strains is very important in terms of clinical epidemiology and food safety. Molecular typing can be used to trace $L$. monocytogenes contamination in food-processing plants. Over the last decade, a vast number of reports of inexpensive and rapid methods to type Listeria spp. have been published $^{8,20,22,62,66)}$. The overall goal has been to develop methods that are more discriminatory than existing serotyping and phage-typing methods. Ribotyping ${ }^{8)}$ and pulsedfield gel electrophoresis of macrorestriction enzyme-digested chromosomal DNA ${ }^{22)}$ has demonstrated good discrimination of Listeria spp. However, since the results are difficult to standardize among laboratories, cooperative studies using these methods are difficult.

Recently, multi-locus sequence typing (MLST) was developed for analyzing the population genetics of bacteria with the advantages of (i) providing unambiguous DNA sequence data that can be easily exchanged and compared via worldwide web databases; (ii) combining PCR and automated DNA sequencing to reduce labor and analysis time; and (iii) providing a discriminatory power comparable to or greater than that provided by fragment-based methods ${ }^{34)}$. As the target of MLST is slowly diversifying housekeeping genes with limited sequence variation, MLST sometimes lacks the discriminatory power required for evaluating the local epidemiology of L. monocytogenes strains ${ }^{3)}$. Consequently, to overcome the problem of low-resolution, a multi-virulence-locus sequence typing (MVLST) scheme was developed for subtyping L. monocytogenes ${ }^{39)}$. Using molecular typing methods of MLST or MLVST, as well as restriction fragment length polymorphism analysis and ribotyping, three major phylogenetic divisions within the species have been identified ${ }^{39,41,61,63)}$ (Fig. 1): Lineage I consists of serotypes $1 / 2 b, 3 b, 4 b, 4 d$ and $4 \mathrm{e}$, and Lineage II consists of serotypes $1 / 2 \mathrm{a}, 1 / 2 \mathrm{c}, 3 \mathrm{a}$ and $3 \mathrm{c}^{41,63)}$. Epidemic strains are mostly found in Lineage I and sporadic strains are found in Lineages I and II, while Lineage III strains are extremely rare and are mostly animal pathogens ${ }^{28)}$.

The complete genomic sequences of $L$. monocytogenes strain EGDe and L. innocua strain CLIP 11262 were also recently determined ${ }^{21)}$. Analysis of these sequences revealed 10.5 and $14 \%$, respectively, to be species-specific sequence for each strain ${ }^{21}$. Among the most striking findings of recent studies is the degree of divergence within L. monocytogenes; one study ${ }^{9}$ ) found that the genetic divergence between Lineages I and II of L. monocytogenes was nearly as great (about 8\%) as interspecies differences between $L$. monocytogenes EGDe serovar 1/2a strain and L. innocua $(10 \%)$. These results are consistent with a previous report $\left.{ }^{25}\right)$ identifying a difference of 39 specific gene fragments between the epidemic L. monocytogenes strain F.4565 and $L$. monocytogenes strain EGDe determined by subtractive hy-

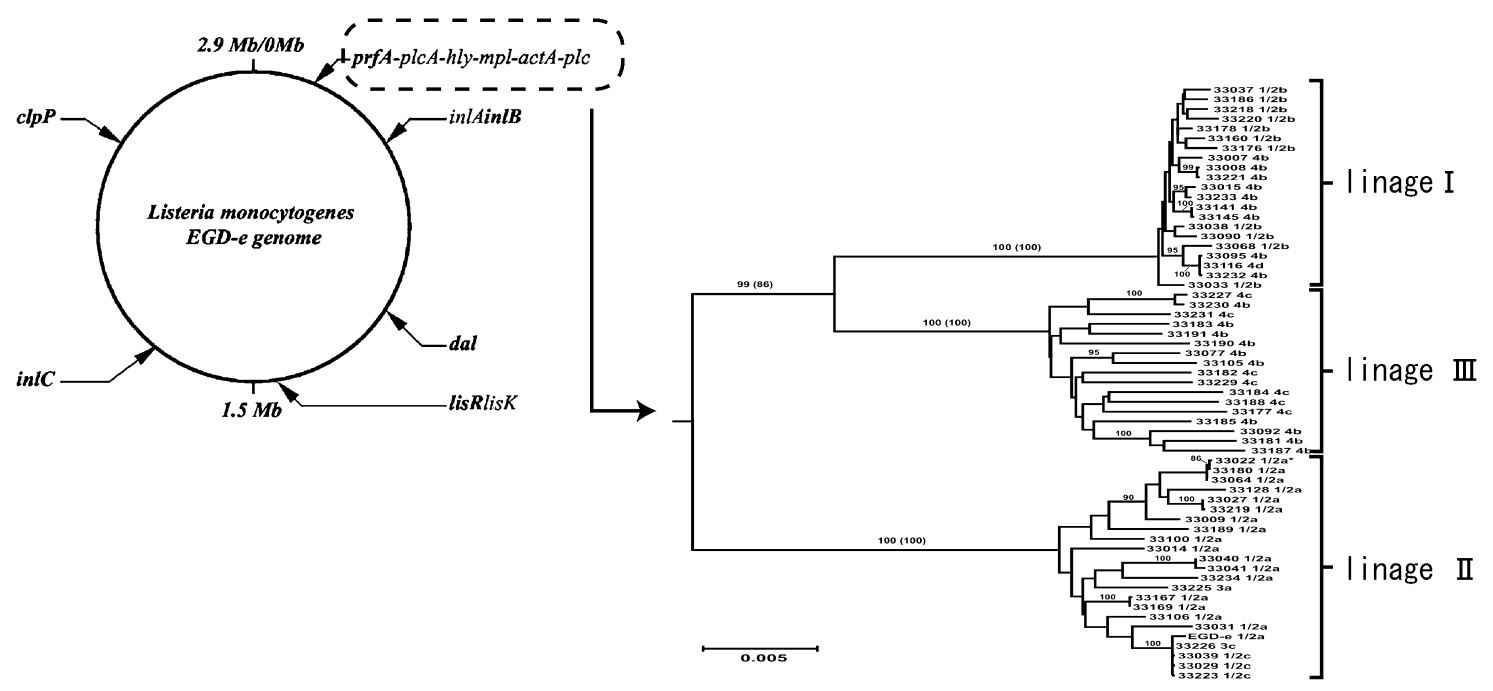

Fig. 1. Neighbor-joining phylogram inferred from an analysis of the combined pVGC sequence data demonstrating three lineages in $L$. monocytogenes populations (redrawn from ref. 61). 
bridization. Based on obvious patterns of gene presence or absence among L. monocytogenes serovars and Listeria spp., it is suggested that early divergence of the ancestral $L$. monocytogenes serovar $1 / 2 \mathrm{c}$ strains from the serovar $1 / 2 \mathrm{~b}$ strains led to the establishment of two major phylogenetic lineages. It is also suggested that one group comprising the serogroup 4 strains branched off the serovar $1 / 2 b$ ancestral lineage, producing (mostly by gene loss) the species $L$. innocua. This is of particular importance since strains of serovar $4 \mathrm{~b}$ mainly represent epidemic $L$. monocytogenes strains and are isolated from severe invasive human cases more frequently than are strains of other serovars, such as serovar 1/ 2a. Another recent study ${ }^{1)}$ using DNA microarrays with 20 strains of $L$. monocytogenes representing six serovars revealed that a majority of epidemic strains of Lineage I grouped together, forming a cluster clearly distinct from the two other Lineage I clusters, which included primarily sporadic and environmental strains. The precise characterization of $L$. monocytogenes is essential for epidemic study of this species. Thus, selective markers for different subpopulations are an essential for the construction of rapid, accurate identification and subtyping methods, which should be powerful tools in public health and food industry investigations.

\section{L. monocytogenes in hosts}

All pathogenic bacteria must take on and overcome host defense systems and must circumvent many different stresses in order to arrive at the site of infection. L. monocytogenes is no exception. These mechanisms include compromising the acid barrier of the stomach, the physical barrier of the epithelial cells lining the gastrointestinal tract, and various immune defenses including the initial onslaught of macrophages. Survival in the presence of bile salt and acidic $\mathrm{pH}$, along with the adhesion of protein and virulence factors required for colonization are important aspects of virulence and have been reviewed elsewhere ${ }^{11,19,47)}$.

The mechanisms by which $L$. monocytogenes invades mammalian cells have been elucidated by a series of detailed and intricate experiments. L. monocytogenes has the amazing ability to cross three significant barriers in humans, namely the intestinal barrier, the blood-brain barrier and the fetoplacental barrier (Fig. 2). Several steps involving a number of specialized molecules have been identified in the infection cells by this pathogen ${ }^{10)}$ : (1) internalin (also called InlA) and InlB (another member of the internalin multigene family, characterized by the presence of leucine-rich repeats), which are responsible for the internalization of $L$. monocytogenes in cultured non-phagocytic cells; (2) listeriolysin, which acts in concert with two phospholipases (PlcA and PlcB) to allow escape from the phagocytic vacuole; and (3) ActA, which mediates actin-based intracytoplasmic movement and cell-cell spreading. Firstly, live bacteria delay phagosomal maturation and targeting by the degradative pathway through rapid lysation of the membrane of the acidified phagosome by listeriolysin O (LLO) acting in concert with the phospholipases PlcA and $\mathrm{PlcB}^{36}$. Then, the bacteria reside freely in the cytoplasm, where they replicate and acquire F-actin-based intracellular motility based on expression of the ActA protein ${ }^{30}$. Subsequently, they invade adjacent cells by cell-to-cell spread ${ }^{51)}$.

The entry of L. monocytogenes into cultured human epithelial cells is mediated by the interaction of an L. monocytogenes surface protein, internalin and its human receptor, E-cadherin ${ }^{32}$. In a transgenic mouse model that expresses human E-cadherin in enterocytes, it was demonstrated that L. monocytogenes could cross the intestinal barrier assisted by internalin. Epidemiological evidence also suggests that internalin allows this pathogen not only to cross the intestinal barrier, but also to cross the placental and blood-brain barriers.

Particularly important among recent findings is the observation that some $L$. monocytogenes isolates express a truncated nonfunctional form of internalin ${ }^{53}$. L. monocytogenes strains carrying a truncated inlA also were significantly less capable of invading Caco-2 cells than isolates with homologous $3^{\prime}$ inlA sequences without a truncation ${ }^{53)}$. A recent study used an immunoblot assay to investigate the expression of internalin in 300 clinical strains obtained in France in a single year and a representative set of 150 strains obtained from food products during the same period ${ }^{27}$. This study demonstrates the critical role of internalin in the pathogenesis of human listeriosis. In another recent study, the truncation of this gene in a number of food and environmental isolates was confirmed with $L$. monocytogenes isolated from the U.S.A ${ }^{42}$. Truncations were also found in $\operatorname{prf} A^{52}$, which regulates the expression of a set of virulence factors, including listeriolysin O (LLO), actin polymerization protein ActA, phospholipases (PlcA and PlcB), and internalins. These recent findings support the usefulness of studying the expression of internalin and other virulence genes as markers of virulence in humans. Although the present prevalent opinion is that all strains of L. monocytogenes should be considered to be pathogenic ${ }^{37)}$, it now seems extremely important to determine whether assessment of the truncation of internalin or other virulence or virulence-associated genes provides a new tool for assessing 


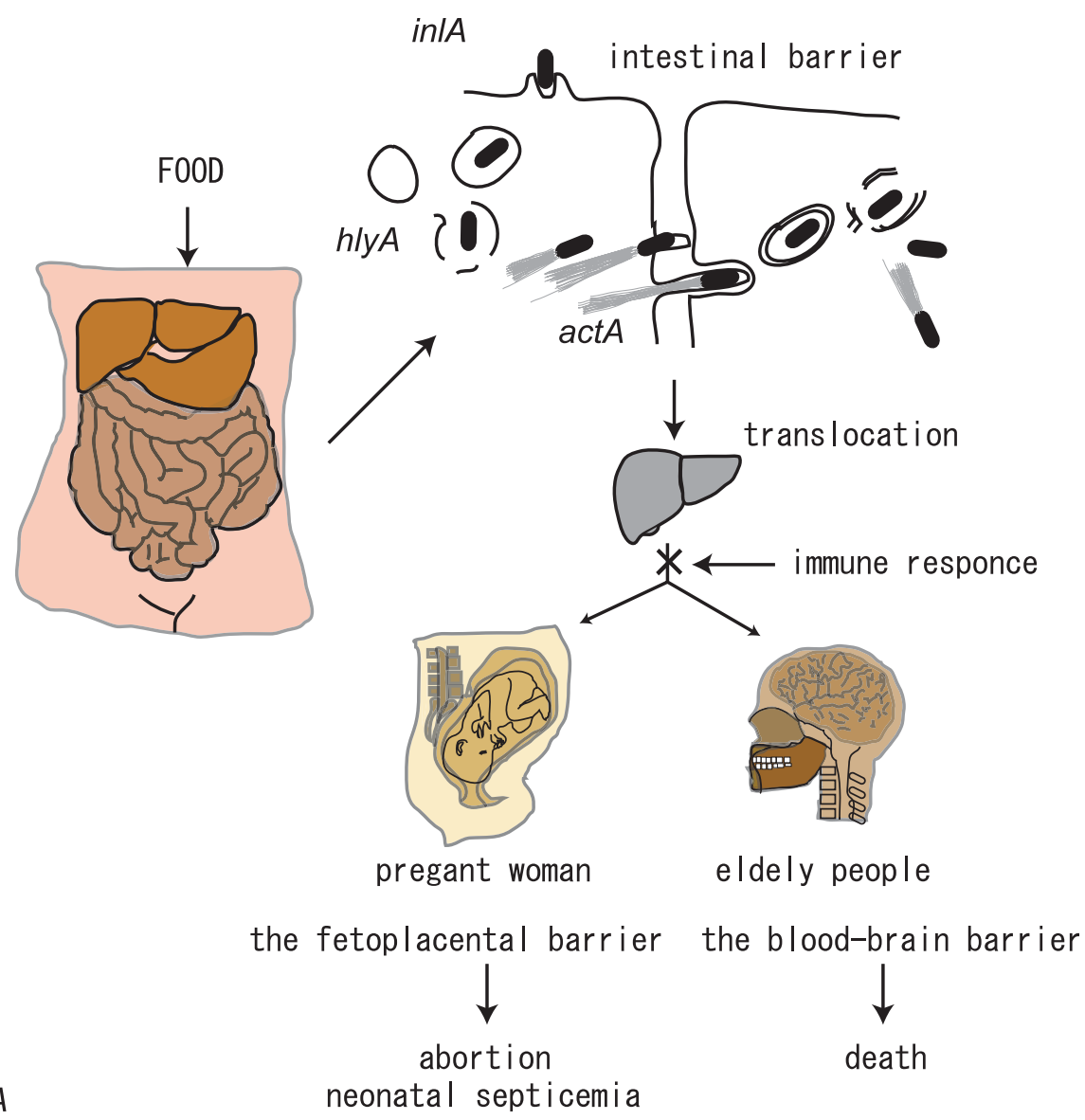

Fig. 2. A schematic representation of how L. monocytogenes invades its host. Following ingestion of contaminated food, L. monocytogenes cross the intestinal barrier and gain access to the liver and spleen via the bloodstream. In immunocompromised individuals and pregnant women, bacteria can cross the tight blood-brain barrier and the maternofetal barrier, respectively and reach the central nervous system and the placenta.

the risk associated with consumption of food products contaminated with L. monocytogenes. An evaluation of any genetic differences between L. monocytogenes populations found in humans and foods will be an important area of study to evaluate the risk of this pathogen in the future.

\section{L. monocyotogenes in food products and ecosystems}

While L. monocytogenes is best known as a food-borne pathogen, in nature it has been found in association with plants and decaying plant tissue. It has been hypothesized, that, as an ecological system, livestock farms may function as natural reservoirs for L. monocytogenes, and ultimately, as a primary source of $L$. monocytogenes contaminating food-processing plants (Fig. 3). Our understanding of the transmission of L. monocytogenes in the farm ecosystem is limited. Many authors agree that a likely scenario for $L$. monocytogenes transmission on farms includes the initial contamination of crops and soil by wildlife, birds or manure used to fertilise fields. Recently, a case-control study of listeriosis in ruminants (cattle, sheep and goats) was conducted on 24 cases and 28 control farms ${ }^{43)}$. The study results indicated that the epidemiology and transmission of L. monocytogenes differed between small-ruminant and cattle farms and that cattle contribute to the amplification and dispersal of L. monocytogenes into the farm environment.

L. monocytogenes is noted for its ability to grow under a wide range of environmental conditions. In particular, it can grow at low or high osmolarity,57), it can effectively adapt to acidic conditions ${ }^{7)}$, and it can grow at temperatures as low as $-0.1^{\circ} \mathrm{C}^{60)}$. Miller ${ }^{40)}$, reported growth of L. monocytogenes Scott $\mathrm{A}$ in brain heart infusion broth, $\mathrm{pH} 7.4$, at $28^{\circ} \mathrm{C}$ as having a water activity $\left(\mathrm{a}_{\mathrm{w}}\right)$ value of 0.92 with $\mathrm{NaCl}$ as a humectant and 0.90 with glycerol as a humectant. The mini- 


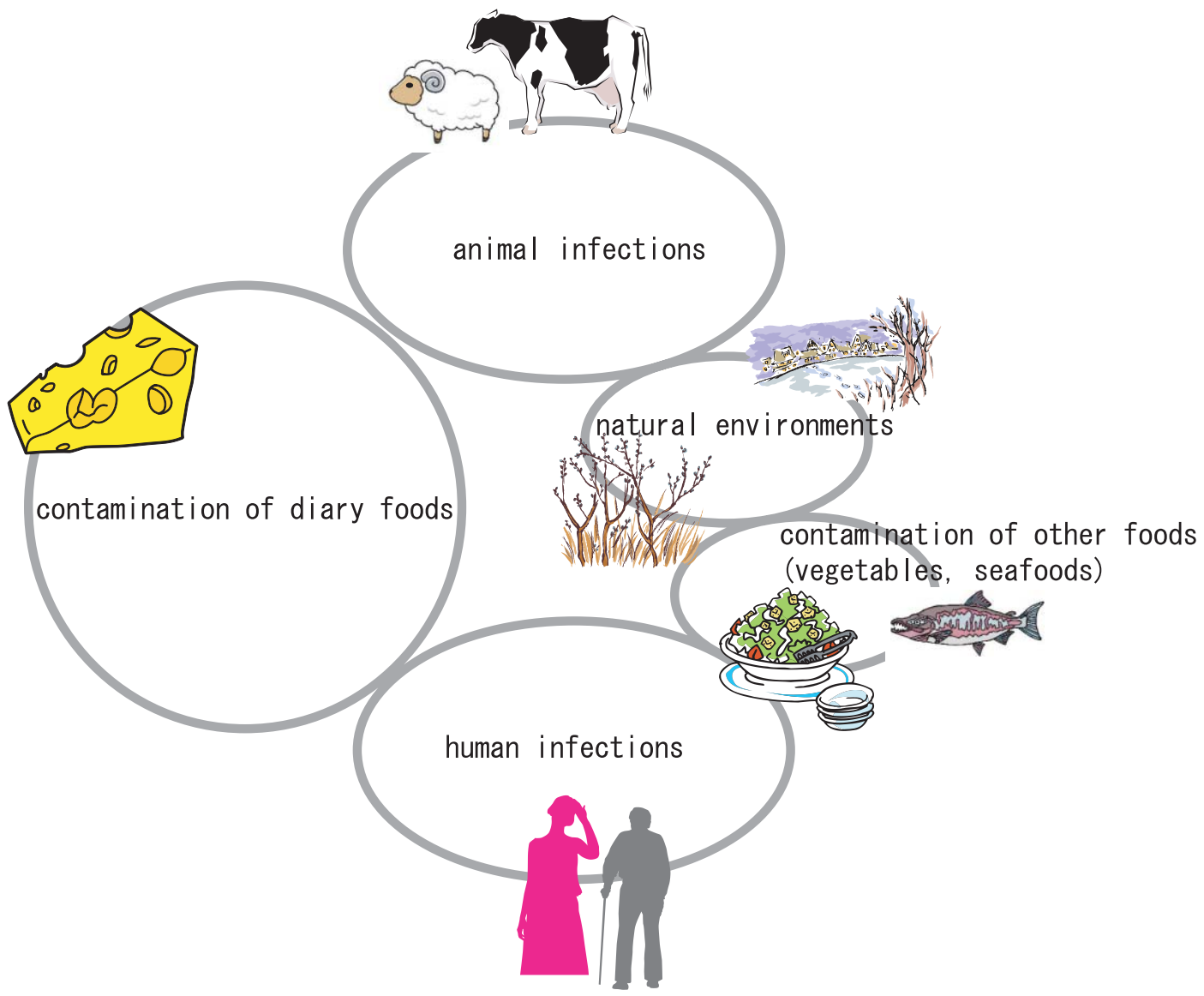

Fig. 3. Different (saprophytic and infective) lifestyles of L. monocytogenes. The bacterium is widely distributed in nature, is able to withstand suboptimal conditions encountered during a saprophytic lifestyle, and eventually adapts to the environmental stresses encountered during the infection of a host.

mum $\mathrm{pH}$ for the growth of L. monocytogenes was 4.3 using $\mathrm{HCl}$ as the acidulant ${ }^{14}$. Of the acid-resistance mechanisms characterized thus far, that of L. monocytogenes is most dependent on the glutamate decarboxylase (GAD) system ${ }^{6}$. The GAD system operates by converting a molecule of glutamate to $\gamma$-aminobutyrate (GABA), thus consuming an intracellular proton and alleviating acidification of the cytoplasm $^{50}$. The intracellular GABA is then exchanged for an extracellular glutamate via an antiporter, and the system is thus primed to consume another intracellular proton. A recent study demonstrated that $L$. monocytogenes possesses a total of three glutamate decarboxylase homologs and two transporters ${ }^{48}$. L. monocytogenes has been reported to grow at temperatures of less than $0^{\circ} \mathrm{C}$ in laboratory media broth $^{60}$. Cold-stress (cold-shock and cold acclimation) proteins whose synthesis is increased after temperature downshifts have been isolated, but for the most part, their identity and functions remain undetermined. A recent study of gene expression in L. monocytogenes in response to growth at $10^{\circ} \mathrm{C}$ showed that the pathogen's acclimation involves amino acid starvation, oxidative stress, aberrant protein synthesis, cell surface remodeling, alterations in degradative metabolism, and induction of global regulatory responses ${ }^{33)}$.

In general, to survive in extreme environments, the ability to respond rapidly to changes in the environment is necessary. In bacteria, these responses are frequently enacted at the transcriptional level. Global changes in transcription are often coordinated by specific sigma factors whose levels and activities fluctuate in response to environmental cues. In $L$. monocytogenes, the gene encoding $\sigma^{\mathrm{B}}(\operatorname{sig} B)$ was identified based on its homology to the $\operatorname{sig} B$ gene from Bacillus subtilis. Phenotypic characterization of L. monocytogenes strains lacking $\operatorname{sig} B$ has shown that $\sigma^{\mathrm{B}}$ plays a role in resistance to various forms of environmental stress, including osmotic, oxidative, and acid stress ${ }^{16-18}$. Also, a broad role for $\sigma^{\mathrm{B}}$-dependent genes in virulence has recently been sug- 
gested for Gram-positive bacteria. A recent study has indicated that, $\sigma^{\mathrm{B}}$ also contributes to the regulation of virulence gene expression in L. monocytogenes ${ }^{29}$.

L. monocytogenes is able to grow in a wide range of environmental conditions and is almost ubiquitous in the environment, which makes the control of this pathogen problematic in the food industry. Vegetables, cheese and meat products have been sources of several outbreaks and sporadic cases $^{54)}$. Seafood products have not been linked to large outbreaks of listeriosis, but five cases of febrile gastroenteritis in Finland were associated with cold smoked salmon contaminated with L. monocytogenes ${ }^{12)}$. Other contaminated seafood products, such as smoked mussels, have been assumed to be sources for sporadic cases of listeriosis ${ }^{2}$. Our recent study revealed that many seafood products eaten raw in Japan, such as raw fish, are widely contaminated with this pathogen ${ }^{23)}$.

Little is known about the physiology of L. monocyotogenes in food products, plants, animals, and other natural environments. Among them, the capacity of this organism to grow in a fresh-cut produce environment, including cabbage, has been well documented ${ }^{15,49)}$. During adaptation to growth in a plant environment, bacteria must be capable of growth with a limited supply of nutrients, biosynthesis, and/ or the transport of building blocks necessary for growth, such as amino acids and nucleotides. Potential forms of stress, such as fluctuations in $\mathrm{pH}$ and osmolarity, must be addressed. In a recent study ${ }^{46}$, the differential display of reverse transcription-PCR fragments amplified with a set of 81 arbitrary primers allowed the isolation and identification of $32 \mathrm{~L}$. monocytogenes gene fragments that showed higher levels of expression under cabbage-associated conditions. This study is only an initial step toward a more detailed understanding of the physiological strategy of L. monocytogenes in natural environments.

\section{Of special interest: why has the incidence of listeriosis in Japan been so low?}

In Japan, the incidence of listeriosis has remained very low and there have not been any outbreaks of this disease. In February 2001, L. monocytogenes serotype 1/2b was isolated from a washed-type cheese during routine monitoring of domestic cheeses ${ }^{35}$. Studies with people who had consumed cheese from the plant revealed that 86 had been infected with L. monocytogenes. Based on the epidemiological and genetic evidence, it appears that the outbreak was caused by cheese. That study was the first to document an incidence of food-borne listeriosis in Japan. However, no other food-borne outbreaks have been recognized in Japan in the past 40 years. One hypothesis for this low incidence of listeriosis is that foods distributed in Japan have lower levels of contamination. Recently, Okutani et al. ${ }^{44)}$ reviewed data on Japanese foods contaminated with L. monocytogenes, mainly from Japanese reports, and found that the proportion of L. monocytogenes, Listeria spp. isolated from foods (meats, natural cheeses, seafood and other ready-toeat foods, for example) in Japan is similar to reports from other countries. Moreover, in Japan, there is significant consumption of ready-to-eat fish products, including raw fish products, and recent studies have revealed that these products are widely contaminated by $L$. monocytogenes ${ }^{23,24,31,65)}$. However, these products have not been implicated in clinical listeriosis in humans to date. Thus, factors other than the contamination rate might be responsible for the low occurrence of listeriosis. At present, almost no information on this issue can be found in published reports. Okutani et al. ${ }^{44)}$ carefully discussed this matter in discriminating each type of contaminated food in Japan. However, a direct relationship between the proportion of food contaminated with $L$. monocytogenes, which is almost the same as that in other countries, and the low incidence of listeriosis in Japan could not be identified. They concluded that other factors need to be analyzed in order to resolve this contradiction. One solution to this problem may be a genetic approach. A genetic difference between L. monocytogenes populations in humans and in fish products consumed in Japan may account for this difference. Further study will be necessary to evaluate this risk based on the functionality of virulence genes such as InlA or Prf $A$ or other virulence genes (full-length vs. truncated), as discussed in the above section, in order to differentiate seafood isolates from clinical isolates. At present, however, this is an area of considerable uncertainty, despite great advances in research on the genetic basis of the virulence of this bacterium.

\section{Conclusion}

In the last 15 years, listeriosis has changed from being an infectious disease of limited importance to one of the most topical food-borne infections. These pathogens are now a major concern for public health authorities and the food industry. Over the same period, the work of various groups in Europe and the United States has made these pathogens one of the best-characterized groups of intracellular parasites at both the molecular and cellular levels. Despite the major progress made towards understanding the mechanisms of virulence of Listeria spp., current insight into the mecha- 
nisms of pathogenesis is still partial and fragmentary. Many questions remain unanswered. From a food microbiologist's point of view, a particularly interesting point is why only certain serovars of L. monocytogenes are associated with listeriosis and certain clones of serovar $4 \mathrm{~b}$ are associated with epidemic episodes of this invasive disease? Answering this questions is very important in order to prevent the unnecessary recall and destruction of valuable food products. Further, as discussed in a previous section of this review, despite the significant consumption of raw fish and readyto-eat fish products in Japan, why have these products as yet never been implicated in clinical listeriosis in humans? There is probably an important difference between the $L$. monocytogenes populations affecting humans and those found in fish products consumed in Japan. In the coming years of the new era of Listeria research, we will certainly witness spectacular progress in these areas and no doubt find answers to these and many other questions.

\section{References}

1) Borucki, M.K., S.H. Kim, D.R. Call, S.C. Smole and F. Pagotto. 2004. Selective discrimination of Listeria monocytogenes epidemic strains by a mixed-genome DNA microarray compared to discrimination by pulsed-field gel electrophoresis, ribotyping and multilocus sequence typing. J. Clin. Microbiol. 42: 52705276.

2) Brett, M.S.Y., P. Short and J. McLauchlin. 1998. A small outbreak of listeriosis associated with smoked mussels. Int. J. Food Microbiol. 43: 223-229.

3) Cai, S., D.Y. Kabuki, A.Y. Kuaye, T.G. Cargioli, M.S. Chung, R. Nielsen and M. Wiedmann. 2002. Rational design of DNA sequence-based strategies for subtyping Listeria monocytogenes. J. Clin. Microbiol. 40: 3319-3325.

4) Centers for Disease Control and Prevention (2000) CDC Surveillance Summaries. MMWR. 49, No. SS-1.

5) Cole, M.B., M.V. Jones and C. Holyoak. 1990. The effect of pH, salt concentration and temperature on the survival and growth of Listeria monocytogenes. J. Appl. Bacteriol. 69: 63-72.

6) Cotter, P.D., C.G.M. Gahan and C. Hill. 2001. A glutamate decarboxylase system protects Listeria monocytogenes in gastric fluid. Mol. Microbiol. 40: 465-475.

7) Davis, M.J., P.J. Coote and C.P. O'Byrne. 1996. Acid tolerance in Listeria monocytogenes: the adaptive acid tolerance response (ATR) and growth-phase-dependent acid resistance. Microbiology 142: 2975-2982.

8) De Cesare, A., J.L. Bruce, T.R. Dambaugh, M.E. Guerzoni and M. Wiedmann. 2001. Automated ribotyping using different enzymes to improve discrimination of Listeria monocytogenes isolates, with a particular focus on serotype $4 \mathrm{~b}$ strains. J. Clin. Microbiol. 39: 3002-3005.

9) Doumith, M., C. Cazalet, N. Simoes, L. Frangeul, C. Jacquet, F. Kunst, P. Martin, P. Cossart, P. Glaser and C. Buchrieser. 2004. New aspects regarding evolution and virulence of Listeria monocytogenes revealed by comparative genomics and DNA arrays.
Infect. Immun. 72: 1072-1083.

10) Drevets, D.A., P.J. Leenen and R.A. Greenfield. 2004. Invasion of the central nervous system by intracellular bacteria. Clin. Microbiol. Rev. 17: 323-347.

11) Dussurget, O., J. Pizarro-Cerda and P. Cossart. 2004. Molecular determinants of Listeria monocytogenes virulence. Annu. Rev. Microbiol. 58: 587-610.

12) Ericsson, H., A. Eklöw, M.-L. Danielsson-Tham, S. Loncarevic, L.-O. Mentzing, I. Persson, H. Unnerstad and W. Tham. 1997. An outbreak of listeriosis suspected to have been caused by rainbow trout. J. Clin. Microbiol. 35: 2904-2907.

13) Farber, J.M. and P.I. Peterkin. 1991. Listeria monocytogenes, a food-borne pathogen. Microbiol. Rev. 55: 476-511.

14) Farber, J.M., F. Coates and E. Daley. 1992. Minimum water activity requirements for the growth of Listeria monocytogenes. Lett. Appl. Microbiol. 15: 103-105.

15) Farber, J.M., S.L. Wang, Y. Cai and S. Zhang. 1998. Changes in populations of Listeria monocytogenes inoculated on packaged fresh-cut vegetables. J. Food Prot. 61: 192-195.

16) Ferreira, A., C.P. O'Byrne and K.J. Boor. 2001. Role of $\sigma^{B}$ in heat, ethanol, acid and oxidative stress resistance and during carbon starvation in Listeria monocytogenes. Appl. Environ. Microbiol. 67: 4454-4457.

17) Ferreira, A., D. Sue, C.P. O'Byrne and K.J. Boor. 2003. Role of Listeria monocytogenes $\sigma^{\mathrm{B}}$ in survival of lethal acidic conditions and in the acquired acid tolerance response. Appl. Environ. Microbiol. 69: 2692-2698.

18) Fraser, K.R., D. Sue, M. Wiedmann and K.J. Boor. 2003. The role of $\sigma^{\mathrm{B}}$ in regulating the compatible solute uptake systems of Listeria monocytogenes: osmotic induction of opuC is $\sigma^{\mathrm{B}}$ dependent. Appl. Environ. Microbiol. 69: 2015-2022.

19) Gahanand, C.G.M. and C. Hill. 2005. Gastrointestinal phase of Listeria monocytogenes infection. J. Appl. Microbiol. 98: 13451353.

20) Gasanov, U., D. Hughes and P.M. Hansbro. 2005. Methods for the isolation and identification of Listeria spp. and Listeria monocytogenes: a review. FEMS Microbiol. Rev. 29: 851-875.

21) Glaser, P., L. Frangeul, C. Buchrieser, C. Rusniok, A. Amend, F. Baquero, P. Berche, H. Bloecker, P. Brandt, T. Chakraborty, A. Charbit, F. Chetouani, E. Couve, A. de Daruvar, P. Dehoux, E. Domann, G. Dominguez-Bernal, E. Duchaud, L. Durant, O. Dussurget, K.D. Entian, H. Fsihi, F.G. Portillo, P. Garrido, L. Gautier, W. Goebel, N. Gomez-Lopez, T. Hain, J. Hauf, D. Jackson, L.M. Jones, U. Kaerst, J. Kreft, M. Kuhn, F. Kunst, G. Kurapkat, E. Madueno, A. Maitournam, J.M. Vicente, E. Ng, H. Nedjari, G. Nordsiek, S. Novella, B. de Pablos, J.C. Perez-Diaz, R. Purcell, B. Remmel, M. Rose, T. Schlueter, N. Simoes, A. Tierrez, J.A. Vazquez-Boland, H. Voss, J. Wehland and P. Cossart. 2001. Comparative genomics of Listeria species. Science 294: 849-852.

22) Graves, L.M. and B. Swaminathan. 2001. PulseNet standardized protocol for subtyping Listeria monocytogenes by macrorestriction and pulsed-field gel electrophoresis. Int. J. Food Microbiol. 65: 55-62.

23) Handa, S., B. Kimura, H. Takahashi, T. Koda, K. Hisa and T. Fujii. 2005. Incidence of Listeria monocytogenes in raw seafood products in Japanese retail stores. J. Food. Prot. 68: 411-415.

24) Hara, Y., M. Izumisawa and K. Ishii. 2003. Contamination of Listeria monocytogenes in Ready-to-Eat Seafoods in Japan. Jpn. J. Food Microbiol. 20: 63-67. (In Japanese) 
25) Herd, M. and C. Kocks. 2001. Gene fragments distinguishing an epidemic-associated strain from a virulent prototype strain of Listeria monocytogenes belong to a distinct functional subset of genes and partially cross-hybridize with other Listeria species. Infect. Immun. 69: 3972-3979.

26) Igimi, S. 2005. Current topics and risk management of Listeria monocytogenes in food. Shokuhin Eiseigaku Zasshi. 46: 237239.

27) Jacquet, C., M. Doumith, J.I. Gordon, P.M.V. Martin, P. Cossart and M. Lecuit. 2004. A molecular marker for evaluating the pathogenic potential of foodborne Listeria monocytogenes. J. Infect. Dis. 189: 2094-2100.

28) Jeffers, G.T., J.L. Bruce, P.L. McDonough, J. Scarlett, K.J. Boor and M. Wiedmann. 2001. Comparative genetic characterization of Listeria monocytogenes isolates from human and animal listeriosis cases. Microbiology. 147: 1095-1104.

29) Kazmierczak, M.J., S.C. Mithoe, K.J. Boor and M. Wiedmann. 2003. Listeria monocytogenes $\sigma^{\mathrm{B}}$ regulates stress response and virulence functions. J. Bacteriol. 185: 5722-5734.

30) Kocks, C., E. Gouin, M. Tabouret, P. Berche, H. Ohayon and P. Cossart. 1992. L. monocytogenes-induced actin assembly requires the act $A$ gene product, a surface protein. Cell 68: 521-531.

31) Kokubo, Y. 1992. Listeria monocytogenes. Jpn. J. Food Microbiol. 9: 13-22. (In Japanese)

32) Lecuit, M. 2005. Understanding how Listeria monocytogenes targets and crosses host barriers. Clin. Microbiol. Infect. 11: 430436.

33) Liu, S.Q., J.E. Graham, L. Bigelow, P.D. Morse and B.J. Wilkinson. 2002. Identification of Listeria monocytogenes genes expressed in response to growth at low temperature. Appl. Environ. Microbiol. 68: 1697-1705.

34) Maiden, M.C., J.A. Bygraves, E. Feil, G. Morelli, J.E. Russell, R. Urwin, Q. Zhang, J. Zhou, K. Zurth, D.A. Caugant, I.M. Feavers, M. Achtman and B.G. Spratt. 1998. Multilocus sequence typing: a portable approach to the identification of clones within populations of pathogenic microorganisms. Proc. Natl. Acad. Sci. USA 95: 3140-3145.

35) Makino, S.-I., K. Kawamoto, K. Takeshi, Y. Okada, M. Yamasaki, S. Yamamoto and S. Igimi. 2005. An outbreak of foodborne listeriosis due to cheese in Japan, during 2001. Int. J. Food Microbiol. 104: 189-196.

36) Marquis, H., H. Goldfine and D.A. Portnoy. 1997. Proteolytic pathways of activation and degradation of a bacterial phospholipase $\mathrm{C}$ during intracellular infection by Listeria monocytogenes. J. Cell Biol. 137: 1381-1392.

37) McLauchlin, J., R.T. Mitchell, W.J. Smerdon and K. Jewell. 2004. Listeria monocytogenes and listeriosis: a review of hazard characterisation for use in microbiological risk assessment of foods. Int J Food Microbiol. 92: 15-33.

38) Mead, P.S., L. Slutsker, V. Dietz, L.F. McCaig, J.S. Bresee, C. Shapiro, P.M. Griffin and R.V. Tauxe. 1999. Food-related illness and death in the United States. Emerg. Infect. Dis. 5: 607-625.

39) Meinersmann, R.J., R.W. Phillips, M. Wiedmann and M.E. Berrang. 2004. Multilocus sequence typing of Listeria monocytogenes by use of hypervariable genes reveals clonal and recombination histories of three lineages. Appl. Environ. Microbiol. 70: 2193-2203.

40) Miller, A. 1992. Combined water activity and solute effects on the growth and survival of Listeria monocytogenes Scott A. J. Food Prot. 55: 414-418.
41) Nadon, C.A., D.L. Woodward, C. Young, F.G. Rodgers and M. Wiedmann. 2001. Correlations between molecular subtyping and serotyping of Listeria monocytogenes. J. Clin. Microbiol. 39: 2704-2707.

42) Nightingale, K.K., K. Windham, K.E. Martin, M. Yeung and M. Wiedmann. 2005. Select Listeria monocytogenes subtypes commonly found in foods carry distinct nonsense mutations in inlA, leading to expression of truncated and secreted internalin $\mathrm{A}$, and are associated with a reduced invasion phenotype for human intestinal epithelial cells. Appl. Environ. Microbiol. 71: 87648772

43) Nightingale, K.K., Y.H. Schukken, C.R. Nightingale, E.D. Fortes, A.J. Ho, Z. Her, Y.T. Grohn, P.L. McDonough and M. Wiedmann. 2004. Ecology and transmission of Listeria monocytogenes infecting ruminants and in the farm environment. Appl. Environ. Microbiol. 70: 4458-4467.

44) Okutani, A., Y. Okada, S. Yamamoto and S. Igimi. 2004. Overview of Listeria monocytogenes contamination in Japan. Int. J. Food Microbiol. 93: 131-140.

45) Okutani, A., Y. Okada, S. Yamamoto and S. Igimi. 2004. Nationwide survey of human Listeria monocytogenes infection in Japan. Epidemiol. Infect. 132: 769-772.

46) Palumbo, J.D., A. Kaneko, K.D. Nguyen and L. Gorski. 2005. Identification of genes induced in Listeria monocytogenes during growth and attachment to cut cabbage, using differential display. Appl. Environ. Microbiol. 71: 5236-5243.

47) Pamer, E.G. 2004. Immune responses to Listeria monocytogenes. Nat. Rev. Immunol. 4: 812-823.

48) Paul, D., Cotter, P.D., S. Ryan, C.G.M. Gahan and C. Hill. 2005. Presence of GadD1 glutamate decarboxylase in selected Listeria monocytogenes strains is associated with an ability to grow at low pH. Appl. Environ. Microbiol. 71: 2832-2839.

49) Prazak, A.M., E.A. Murano, I. Mercado and G.R. Acuff. 2002. Prevalence of Listeria monocytogenes during production and postharvest processing of cabbage. J. Food Prot. 65: 1728-1734.

50) Richard, H.T. and J.W. Foster. 2003. Acid resistance in Escherichia coli. Adv. Appl. Microbiol. 52: 167-186.

51) Robbins, J.R., A.I. Barth, H. Marquis, E.L. de Hostos, W.J. Nelson and J.A. Theriot. 1999. Listeria monocytogenes exploits normal host cell processes to spread from cell to cell. J. Cell Biol. 146: 1333-1350.

52) Roche, S.M., P. Gracieux, E. Milohanic, I. Albert, I. VirlogeuxPayant, S. Témoin, O. Grépinet, A. Kerouanton, C. Jacquet, P. Cossart and P. Velge. 2005. Investigation of specific substitutions in virulence genes characterizing phenotypic groups of low-virulence field strains of Listeria monocytogenes. Appl. Environ. Microbiol. 71: 6039-6048.

53) Rousseaux, S., M. Olier, J.P. Lamaitre, P. Piveteau and J. Guzzo. 2004. Use of PCR-restriction fragment length polymorphism of inlA for rapid screening of Listeria monocytogenes strains deficient in the ability to invade Caco-2 cells. Appl. Environ. Microbiol. 70: 2180-2185.

54) Schuchat, A., B. Swaminathan and C. Broome. 1991. Epidemiology of human listeriosis. Clin. Microbiol. Rev. 4: 169-183.

55) Schuchat, A., K. Robinson, J.D. Wenger, L.H. Harrison, M. Farley, A.L. Reingold, L. Lefkowitz, B.A. Perkins and the Active Surveillance Team. 1997. Bacterial meningitis in the United States in 1995. N. Engl. J. Med. 337: 970-976.

56) Siegman-Igra, Y., R. Levin, M. Weinberger, Y. Golan, D. Schwartz, Z. Samra, H. Konigsberger, A. Yinnon, G. Rahav, N. 
Keller, N. Bisharat, J. Karpuch, R. Finkelstein, M. Alkan, Z. Landau, J. Novikov, D. Hassin, C. Rudnicki, R. Kitzes, S. Ovadia, Z. Shimoni, R. Lang and T. Shohat. 2002. Listeria monocytogenes infection in Israel and review of cases worldwide. Emerg. Infect. Dis. 8: 305-310.

57) Sleator, R.D., C.G.M. Gahan and C. Hill. 2003. A postgenomic appraisal of osmotolerance in Listeria monocytogenes. Appl. Environ. Microbiol. 69: 1-9.

58) Tompkin, R.B. 2002. Control of Listeria monocytogenes in the food-processing environment. J. Food Prot. 65: 709-725.

59) Vázquez-Boland, J.A., M. Kuhn, P. Berche, T. Chakraborty, G. Domínguez-Bernal, W. Goebel, B. González-Zorn, J. Wehland and J. Kreft. 2001. Listeria pathogenesis and molecular virulence determinants. Clin. Microbiol. Rev. 14: 584-640.

60) Walker, S.J., P. Archer and J.G. Banks. 1990. Growth of Listeria monocytogenes at refrigeration temperatures. J. Appl. Bacteriol. 68: $157-162$.

61) Ward, T.J., L. Gorski, M.K. Borucki, R.E. Mandrell, J. Hutchins and K. Pupedis. 2004. Intraspecific phylogeny and lineage group identification based on the prfA virulence gene cluster of Listeria monocytogenes. J. Bacteriol. 186: 4994-5002.
62) Wernars, K., P. Boerlin, A. Audurier, E.G. Russell, G.D. Curtis, L. Herman and N. van der Mee-Marquet. 1996. The WHO multicenter study on Listeria monocytogenes subtyping: random amplification of polymorphic DNA (RAPD). Int. J. Food Microbiol. 32: $325-341$.

63) Wiedmann, M., J.L. Bruce, C. Keating, A.E. Johnson, P.L. McDonough and C.A. Batt. 1997. Ribotypes and virulence gene polymorphisms suggest three distinct Listeria monocytogenes lineages with differences in pathogenic potential. Infect. Immun. 65: 2707-2716

64) Wing, E.J. and S.H. Gregory. 2000. An updated model of cellmediated immunity-listeriosis: clinical and research aspects. Allergy Asthma Proc. 21, pp. 209-214.

65) Yamazaki, K., T. Tateyama, Y. Kawai and N. Inoue. 2000. Occurrence of Listeria monocytogenes in retail fish and processed seafood products in Japan. Fish. Sci. 66: 1191-1193.

66) Zheng, W. and S. Kathariou. 1995. Differentiation of epidemicassociated strains of Listeria monocytogenes by restriction fragment length polymorphism in a gene region essential for growth at low temperatures $\left(4^{\circ} \mathrm{C}\right)$. Appl. Environ. Microbiol. 61: 4310 4314. 